\title{
Problems and Solutions of Rural Power Grid Construction Yu Meng
}

School of Electrical \& Electronic Engineering, North China Electric Power University, Beijing, China 727546860@qq.com

Keywords: Rural area; Power grid; Voltage quality; Management

\begin{abstract}
This paper points out some prominent problems remained in the construction of power grids in rural areas and clarify the importance of solving the problem by the way, then it analyzes the causes of the problems from several different aspects based on the background of certain problems. Finally, some constructive suggestions to improve the current status of the rural power grid are given for reference.
\end{abstract}

\section{Introduction}

With the adjustment of rural industrial structure and the implementation of home appliances' benefiting policy carried out by government, a large number of high-power household appliances enter into ordinary family[1].Increasing demand of power supply raises widespread concerns about rural power grid construction. Obviously, in order to promote urban and rural integration and improve the quality of rural residents' life, to enhance the level of rural power grid construction has become a crucial factor.

\section{Prominent Problem}

Since the reform and opening-up, especially in recent years, due to the rapid development of rural economy, a large number of rural residents expand the original living range, resulting in that the original power grid lines continue to extend, and mostly changes are that the temporary line transfer into a long-term power supply[1].In addition, the old equipment is also a very serious problem in rural area. As shown in Fig. 1, the difference between urban and rural power grid equipment is obvious.

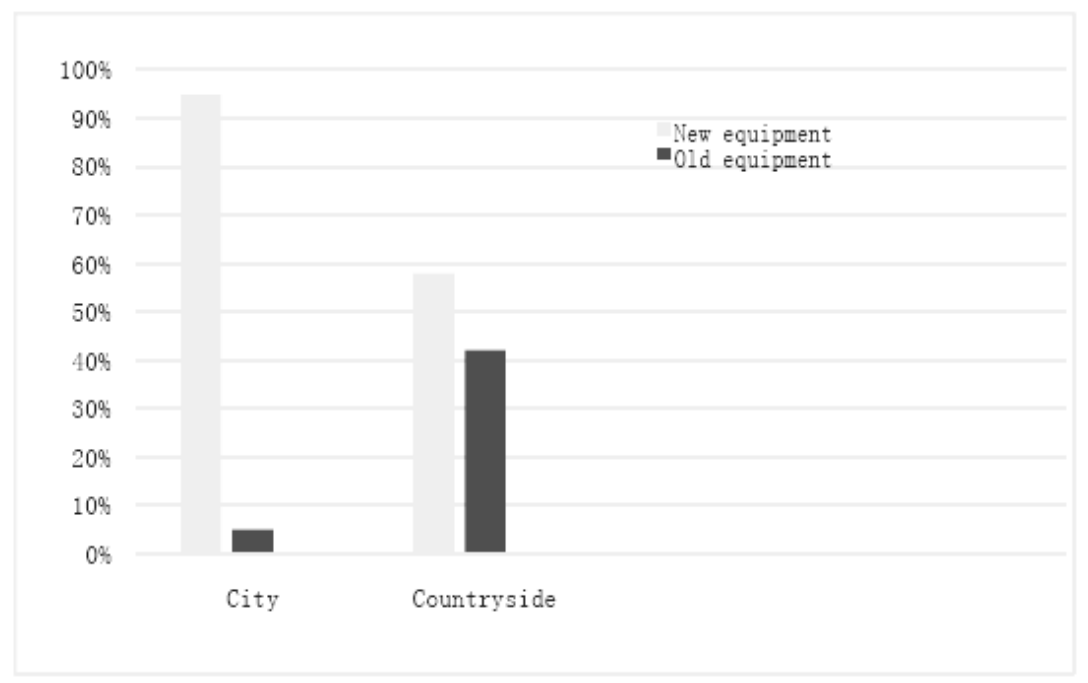

Figure 1. Finite Distribution ratio of urban and rural power grid equipment

At the end of the last century, rural residents began to set up large-scale grid lines, most of the home appliances' power were very small, electricity consumption was relatively little correspondingly. Each village community set up the transformer mainly used for farmland irrigation and sideline 
processing and breeding, the actual situation determined that the general distribution room was constructed outside the field, while the village rarely built and reserved land for the power-distribution room . Most of the erection of the distribution line was a thin wire, thus the power supply radius was large.

From the geographical point of view, residents' living area, for example, the mountainous area and hilly area, are relatively scattered, showing a small gathered but large decentralized pattern, an administrative village is often surrounded by ten or even more than a dozen natural villages which contains different number of households[3]. As the conditions are limited, usually three to five natural villages share a distribution transformer. Problem as single-phase power supply, long power supply radius is particularly prominent.

\section{Analysis of the Causes of the Problems}

Historical Factors. The Regional power-grid lines of the old public distribution area are aging. Small wire cross section, low degree of insulation, roundabout power supply, confused wiring, all those phenomenon result in so serious line loss and power loss that the voltage-drop at the end of the line is significant[4].In order to improve the terminal voltage, we will generally adjust the gear of the transformer to the highest gear, try to keep that the voltage in the same area Satisfies the demand of both the ultra-upper limit voltage users near the distribution area and the lower limit voltage users at the end of the line's extremity.

As the early grid planning and construction lagging behind, the existing ten-thousand volts of power grid structure is weak[5].Long power supply distance, roundabout power supply, line aging, small diameter and heavy load results in low transformer outlet voltage near the back-end distribution area.

Considering from User'S Side. Residents' electrical consumption increases rapidly, electricity load rises correspondingly. The distribution voltage failed to increase in time, resulting in insufficient distribution capacity, high-load rate, small household capacity and low terminal voltage, which cannot meet the needs of users[6].

Seasonal load is prominent. When the load is in the valley, the distribution transformer gets sufficient capacity and the voltage is normal. While during the peak period in the winter or summer, as shown in Table 1, the residents use air conditioning, electric heater, electric pots and some other high-power household appliances at the same time. This is the time when voltage fluctuations occur easily, especially in the late-peak hours, power-distribution transformer's transient overload lead to residential voltage quality decline of a large area, household appliances can't work effectively as a result.

Dynamic load is prominent, too. The community residents who run a small workshop or agricultural products processing base usually use relatively large power equipment, the manufacturing time is always concentrated. The surge due to the use of electrical load results in low grid voltage. But the distribution gets rich capacity in peacetime with no load. So the power supply contradictions are quite prominent[7].

Table 1 The proportion of air conditioning electricity consumption in different seasons

\begin{tabular}{|c|c|c|}
\hline & spring or autumn & Summer or winter \\
\hline proportion & less than $5 \%$ & more than $30 \%$ \\
\hline
\end{tabular}

Considering from Management Department. Daily operation and maintenance is not in place, the department who gets responsibilities for the distribution area cannot dynamically adjust the distribution transformer's split gear, resulting in that the distribution transformer's gear does not match the actual load demand. Distribution transformer station's location is unreasonable and inadequate, always away from the load center. The power supply radius is too large and the terminal 
voltage-drop is significant. In addition, automatic data collection facilities in the distribution area are not complete, some extremely bad phenomenon cannot be detected and dealt with in time.

The power load control about the integrated power-distribution-station line is not in place, single-phase load is heavy, three-phase voltage is imbalance, affecting the voltage quality. Monitoring changes of load of the residents' side is not in place, which is also a crucial factor. Because related departments fail to predict, plan and arrange ahead of time, the guidance leading people to use electricity avoiding the peak period is not effective. Otherwise, when the new users, especially the new sideline food processing and other high-power users, apply electricity program, they usually don't fully consider the distribution lines and the equipment's load capacity.

Other Factors. Mountainous areas, hills, lakes and other remote areas' residents live decentralizing, the electricity consumption is relatively small, but part of the line power supply radius is too long, the diameter is too small, the distribution transformer's distribution is not enough[8].Some specific performance are that the area close to the distribution transformer get normal voltage, while places away from the distribution center get significant voltage-drop .

The line failed to balance the community residents' load, and thus most residents share a phase-line power supply, which results in that the three-phase line load is not balanced, problems as single-phase voltage-drop are serious.

\section{Several Targeted Advice}

Improve the Power Supply Capacity of the Distribution Area. On the one hand, we should increase the line construction efforts, optimize the line path, extend the high-voltage line, shorten the low-voltage line, improve the line's insulated rate, improve the capacity of the distribution stations' line's power supply. On the other hand, we should give priority to small- capacity power supply to transform.

For the rural distribution area which is overload due to the large fluctuation of the seasonal load, measures like combined change, capacity change and using on-load tap changing transformer can be used. For the distribution area which is overload due to the large fluctuation of the daily load, measures as increasing the transformer capacity and replacing the on-load voltage transformer or overload-capacity transformer can be used[9].

For the area where people live a concentrated life and power supply radius is exceeded, it is necessary to increase the distribution point and increase the wire's cross-section. For the area where people live a scattered life and power supply radius is exceeded, we can use small-capacity and single-phase transformer to change the way to supply electric power.

For the area where three-phase voltage is unbalanced, related department should investigate residents' living appliances or some agricultural equipment actually, and then try to adjust each phase's line load averagely

Enhance the Ability to Compensate Centralized of Public Distribution. According to the actual load's situation, power sector should install automatic device tracking the reactive power compensation to provide real-time compensation. In addition, according to the characteristics of rural community load's fluctuation, power sector should optimize the capacity's combination of public power-distribution transformer to improve the capacitor-input rate.

Strengthen the Management of Users' Demand. Make full use of electricity-information collecting system to collect information of distribution and user load's growth, carry out the analysis of the characteristics and provide basis for construction and facilities' running in the future.

Carry out management of public power-distribution station to avoid users' power use lifting high, guide and encourage high-load users to use power at the right time actively. Recent years, the ladder-electricity pricing policy is a good example[10].

Establish a voltage monitoring system and focus on it's continuous improvement. Use electrical information collecting system and intelligent distribution network monitoring platform and other technical means to realize the goal of real-time monitoring. After that, according to the voltage 
changes, develop corrective measures to ensure that the power supply voltage run at the right level in time.

Standardize the Management of Distribution Area. Establish the program about reactive-power equipment. Develop reactive-power equipment's management while it's running. Strengthen the management of operation and maintenance of power supply facilities, solve reactive-power equipment's problems timely so that the equipment can work steadily. Otherwise, combined with different seasons, different periods of load's curve and voltage's curve, timely increase or decrease voltage-reactive power equipment.

Strengthen the management of daily operation and maintenance, establish and improve the inspecting mechanism, make preparation for line maintenance and renovation plan timely.

According to the actual operation of the distribution transformer's load's conditions to determine the increasing capacity. Distribution station management unit should regularly release information about each distribution transformer's power supply capacity, and report to higher production department as the basis for the development of customer's power supply program.

Improve Power-use-service's Quality of Community Residents. Establish and improve users' files. Faced with the occurrence of different situations, take effective management and technical measures. Once situations appear, solve the problems immediately and try to provide rural residents with high-quality electrical services.

\section{Summary}

As credible data shows, rural electricity consumption has become more than a half consumption of the electricity sold by the grid, showing that the rural power grid facilities' updating task is imminent, otherwise it will become a major factor to curb the development of rural economy. Of course, the rural power grid upgrading work can not be achieved overnight. It is a long-term task that will take several years, and it needs funds, technology and many other supports. But we have reason to believe that after taking some measures, the rural power grid construction level will slowly catch up with the city's construction level.

\section{References}

[1] Kenneth Lee, Eric Brewer, Carson Christiano, Francis Meyo, Edward Miguel, Matthew Podolsky, Javier Rosa, Catherine Wolfram, Electrification for "Under Grid" households in Rural Kenya, Development Engineering(2016)

[2] Sun Wei, Jia Yulu, Analysis on the Situation of power supply and Demand in Shandong[J], Electricity(2008)

[3] Gao Jianlai, Liu Fang, Sdudy on the new rural construction of the capital management mode reform[J],Accounting research (2008)

[4] Mashael Yazdanie, Martin Densing, Alexander Wokaun, The role of decentralized generation and storage technologies in future energy systems planning for a rural agglomeration in Switzerland, Energy Policy(2016)

[5] A.S. Sánchez,E.A. Torres, R.A. Kalid. Renewable energy generation for the rural electrification of isolated communities in the Amazon Region, Renewable and Sustainable Energy Reviews, (2015)

[6] G.D. Kamalapur, R.Y. Udaykumar, Rural electrification in India and feasibility of Photovoltaic Solar Home Systems, International Journal of Electrical Power \& Energy Systems(2011)

[7] Sun Shouguang, Discussion on the Prospective Mode of China Power Grid Interconnection in View of Load Density[J] ,Electric Power Planning and Engineering Institute(1999)

[8] Valentin Bertsch, Margeret Hall, Christof Weinhardt, Wolf Fichtner, Public acceptance and preferences related to renewable energy and grid expansion policy: Empirical insights for Germany, Energy(2016) 
[9] The Principles and Methods of Power Development Planning in the Market Economic Situation of China[J],Electricity(1999)

[10 Andrew M. Tanner, Alison L. Johnston, The Impact of Rural Electric Access on Deforestation Rates, World Development(2017)

[11] Ahmed M.A. Haidar, Kashem Muttaqi, Danny Sutanto, Smart Grid and its future perspectives in Australia, Renewable and Sustainable Energy Reviews(2015) 